\section{俩 Heighten Science P U B L I C I T I O N S Corporation ISSN 2574-0350}

\title{
Automatic control and protection of Coal Conveyor System using PIC
}

\author{
Mumtaj $\mathrm{S}^{1}$, Dhamodharan $\mathrm{K}^{2 *}$, Hari Prasad $\mathrm{K}^{2}$ and Kamesh \\ Gautham B2 \\ ${ }^{1}$ Assistant Professor, India \\ ${ }^{2}$ Assistant Professor, UG Student, Department of Electrical and Electronics Engineering, Sri \\ Ramakrishna Engineering College, Coimbatore, Tamil Nadu, India
}

\begin{abstract}
*Address for Correspondence: Dhamodharan K, Assistant Professor, UG Student, Department of Electrical and Electronics Engineering, Sri Ramakrishna Engineering College, Coimbatore, Tamil Nadu, India, Email: dhamodhamo100@ gmail.com
\end{abstract}

Submitted: 11 April 2018

Approved: 03 May 2018

Published: 04 May 2018

Copyright: @ 2018 Mumtaj S, et al. This is an open access article distributed under the Creative Commons Attribution License, which permits unrestricted use, distribution, and reproduction in any medium, provided the original work is properly cited.

Keywords: Conveyor system; PIC microcontroller; Temperature sensor; Infra-red sensor; DC Motor; Cooling fan; Temperature sensing circuit; Tear detecting circuit

\section{Abstract}

The Coal conveyor system forms an integral part in Thermal Power plant owing to the fact that the overall efficiency of the plant is dependent on the rate at which the coal is carried to the crusher unit. But, as of now, only manual labors are employed to regularly monitor the operation of conveyor system which is highly risky. Hence, by means of a Microcontroller like PIC makes the controlling process much easier. The flaws that occur in the conveyor system are mostly due to the temperature at which the coal is carried and also due to the attrition in the belt. By means of a Temperature sensor and an IR sensor this could be regularly monitored and during any abnormal situation, this initiate Cooling fan in case of high temperature and signals an alarm whenever there is any fault in the system.

\section{Introduction}

The Conveyor system is considered to be the least important system in Thermal Power station and hence Humans are employed to look after it on a shift basis. The Conveyor system in a Thermal Power station consists of various components like Conveyor gallery, Belt sway switch, Pull cord switch, Self-aligning roller, Zero speed switch, Counter weight. But apart from this, Conveyor belt has a significant role to carry the Coal without affecting its combustion quality to the Coal Crushing unit for further process. Normally, the Conveyor belt length varies from $300 \mathrm{~m}$ to $1000 \mathrm{~m}$ on an average basis. So, it becomes a tedious process to make sure that they are in perfect condition throughout the operating days without any damage in the belt. Since, mainly humans are employed in the Handling plants, they tend to make errors and any small such errors may cause a huge loss to life and property.

\section{Existing system}

At present, in most Thermal Power plants, there is no specific automated system used to monitor the status of the Coal conveyor system although, the rest of the Power plant is controlled and protected by means of advanced system like PLC and SCADA. The existing method in the Conveyor system makes use of manual skilled labor to regularly monitor the Conveyor belt. In case, of any fault identification the entire Conveyor system is turned off on a temporary basis until the fault is rectified completely. This affects the overall efficiency of the plant by minimizing the operation period which ultimately results to low output power. Hence, it is high time to switch over to automated system from manual monitoring techniques.

\section{Proposed system}

In the Proposed system, several features are employed to minimize the work load 
on humans. The system consists of LM 35 Temperature sensor and a Tear detecting IR sensor to detect any flaws in the Conveyor belt. The temperature sensor senses the temperature of the surroundings regularly, and whenever there is any rise in temperature, the signal passes to the PIC microcontroller which in turn switches on the Cooling fan thereby to reduce the excess temperature. Also, whenever there is any attrition in the Conveyor belt due to its quality or life-span, the Infra- Red sensor detects the flaw in the belt. This in turn makes the Microcontroller to stop the Conveyor system and initiate the alternative another conveyor system so that the Output power of the plant is not affected. (Figure 1).

\section{Hardware components}

A. Power supply: The Power supply available mostly is $230 \mathrm{~V}$ AC. But this power is converted to $+5 \mathrm{~V}$ DC since, the optimal input power for the PIC Microcontroller is $+5 \mathrm{~V}$ DC. This is made possible by means of a Converter circuit consisting of various power electronic devices.

B. PIC microcontroller: The PIC microcontroller is chosen since it has a less power consumption compared to other microcontrollers. Main characteristic of this Microcontroller is that it can connect analog devices directly without any external circuitry and uses them with ease. Programming is also very easy when compared to other microcontrollers. It has the functions of reading the data available at the sensor output, send the data to the LCD display and operate the other motor in case of any faults in the belt. (Figure 2).

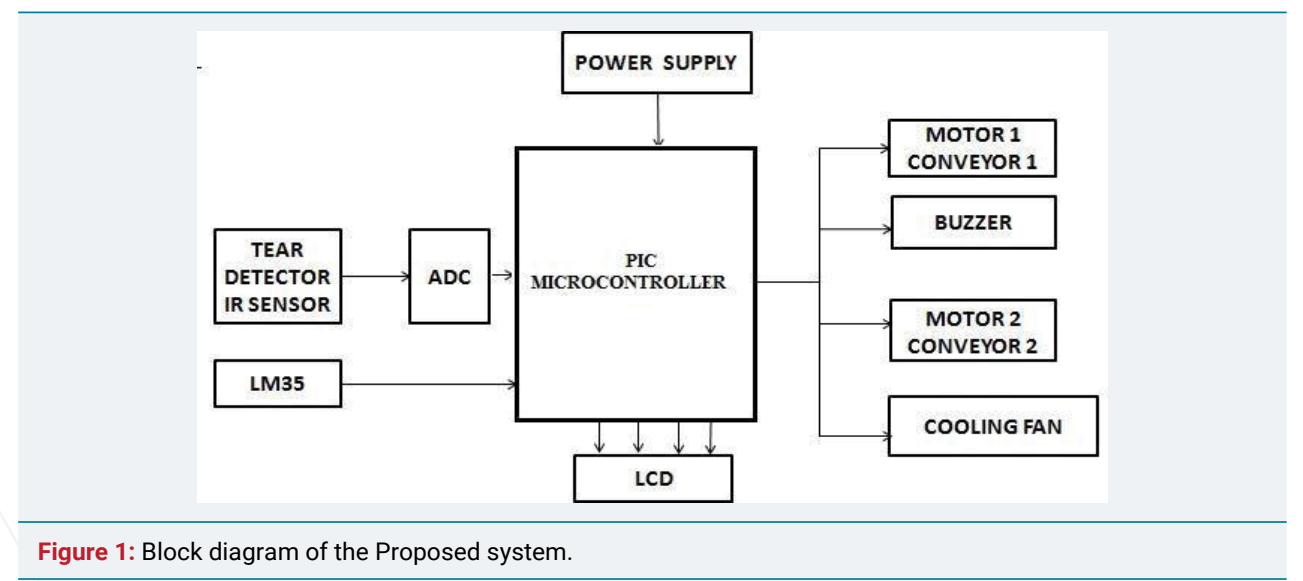

Figure 1: Block diagram of the Proposed system.

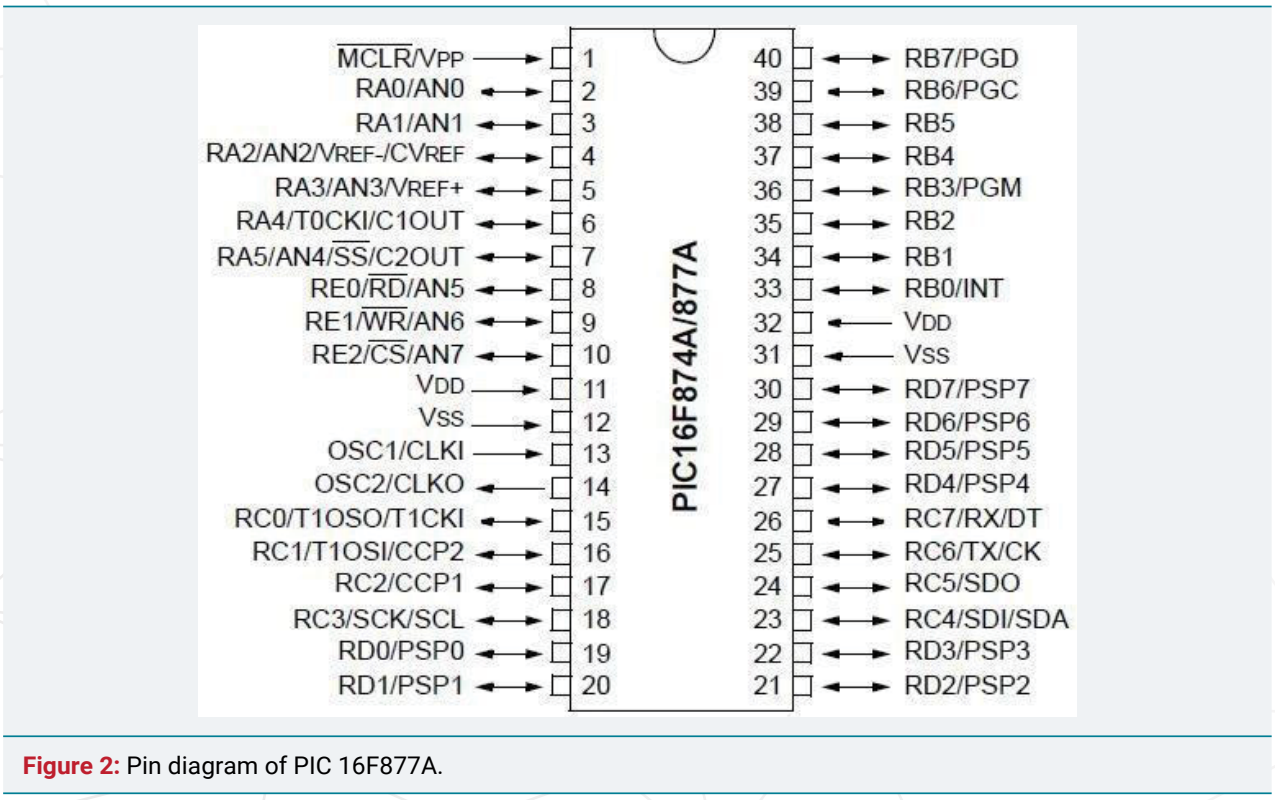


C. Temperature sensor: The temperature sensor used in this proposed system is LM 35. It is a 3- pin analog temperature sensor which has high precision than mostly available sensors. The Pin-1 senses the temperature in the surroundings and gives output as a Voltage through Pin-2. The main advantage of using this sensor is that it can be operated at any harsh and extremely hot climatic conditions.

D. IR sensor: The two important components of an IR sensor are the IR LED and the Photo-diode. They are mostly used to detect any object motion and any deviation in a smooth surface. In this project, the IR sensor is employed to detect any flaws that occur in the smooth surface of the Coal conveyor belt.

E. DC motor: A DC motor is a class of rotary electrical machines that converts direct current energy into mechanical energy. The most common types rely on the forces produced by magnetic fields. The Operating range of the motor used in this project is $4 \mathrm{~V}$ to $12 \mathrm{~V}$. The Speed is $30 \mathrm{rpm}$ at 12 Vand Torque range is $5 \mathrm{~kg} / \mathrm{c}$. The motors are designed to reduce the output speed while increasing its torque. The increasing torque is inversely proportional to reduction in speed.

F Buzzer: The project makes use of electric buzzer to alert the persons in the remote stations in the thermal power plant. The Operating voltage of the buzzer is $1.5 \mathrm{~V}$ to $12 \mathrm{~V}$. It produces sound range from 2 to $4 \mathrm{KHz}$. It is used to produce an alarming signal whenever there is fault in the system.

G. Cooling fan: The Cooling fan used in this project is a Brushless DC motor. The cooling fan starts to operate whenever there is abnormal or a high temperature is prevailing in the Coal conveyor belt resulting damage to it. The operating voltage of the Brushless DC motor is $8 \mathrm{~V}$ to $12 \mathrm{~V}$. It operates when the LM 35 senses high temperature and initiates the PIC microcontroller to act accordingly.

\section{Circuit description}

A. Temperature sensing circuit: The Temperature sensing circuit mainly consists of LM 35 to regularly monitor the temperature of the coal in the Thermal Power station. Whenever the temperature reaches a high value or above the nominal range, a Fan is automatically turned in to remove the excess heat from the coal and to prevent any damage to the system. The temperature sensing circuit involves the use of the LM35 temperature sensor. The third pin connected to the ground and first pin connected to the $5 \mathrm{~V}$ supply. The output from the second pin is connected to the channel AN1 of the microcontroller. A potentiometer is also connected between the second pin and the ground to calibrate the temperature sensor during the occurrence of faults. (Figure 3).

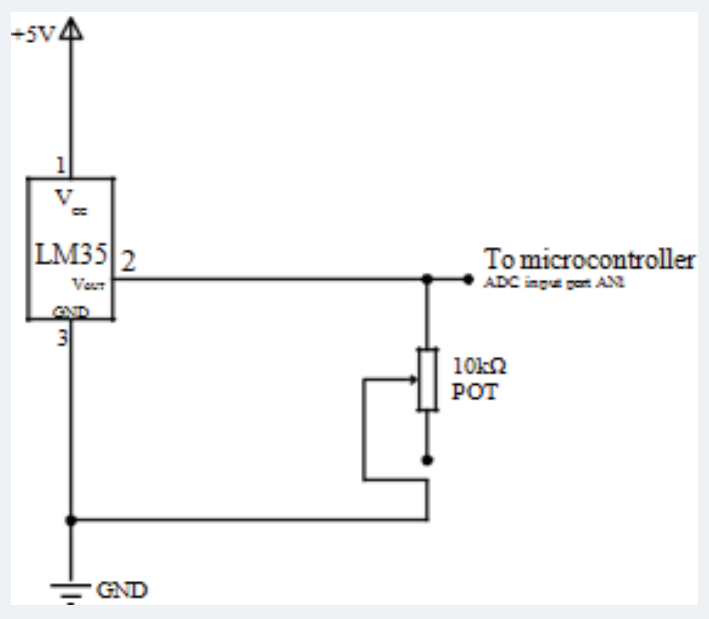

Figure 3: Temperature sensing circuit. 
B. Tear detecting circuit: The Tear detecting circuit relies on the operation of an Infra-Red LED and a Photodiode. The combination of IR-LED and Photodiode detects any fault or abnormal deviation from the smooth surface. Whenever there is such deviation it integrates the voltage and compares it with the pre-set value. Mainly, these Tear detecting circuit is employed in areas profound to object motion (Figure 4).

C. Overall circuit diagram: The temperature sensor LM35 is placed above the Conveyor belt to regularly monitor the temperature of the coal. The tear detecting IR sensor is placed below the Conveyor system to detect any flaws like tear and cracks in the system. The output of these sensors is provided to the PIC microcontroller. PIC microcontroller is programmed to compare temperature in the system also to initiate the rotation of another conveyor belt in case of any faults in the belts. The temperature of the coal carried in the Conveyor belt and the working status of the entire system is shown in the LCD display regularly (Figure 5).
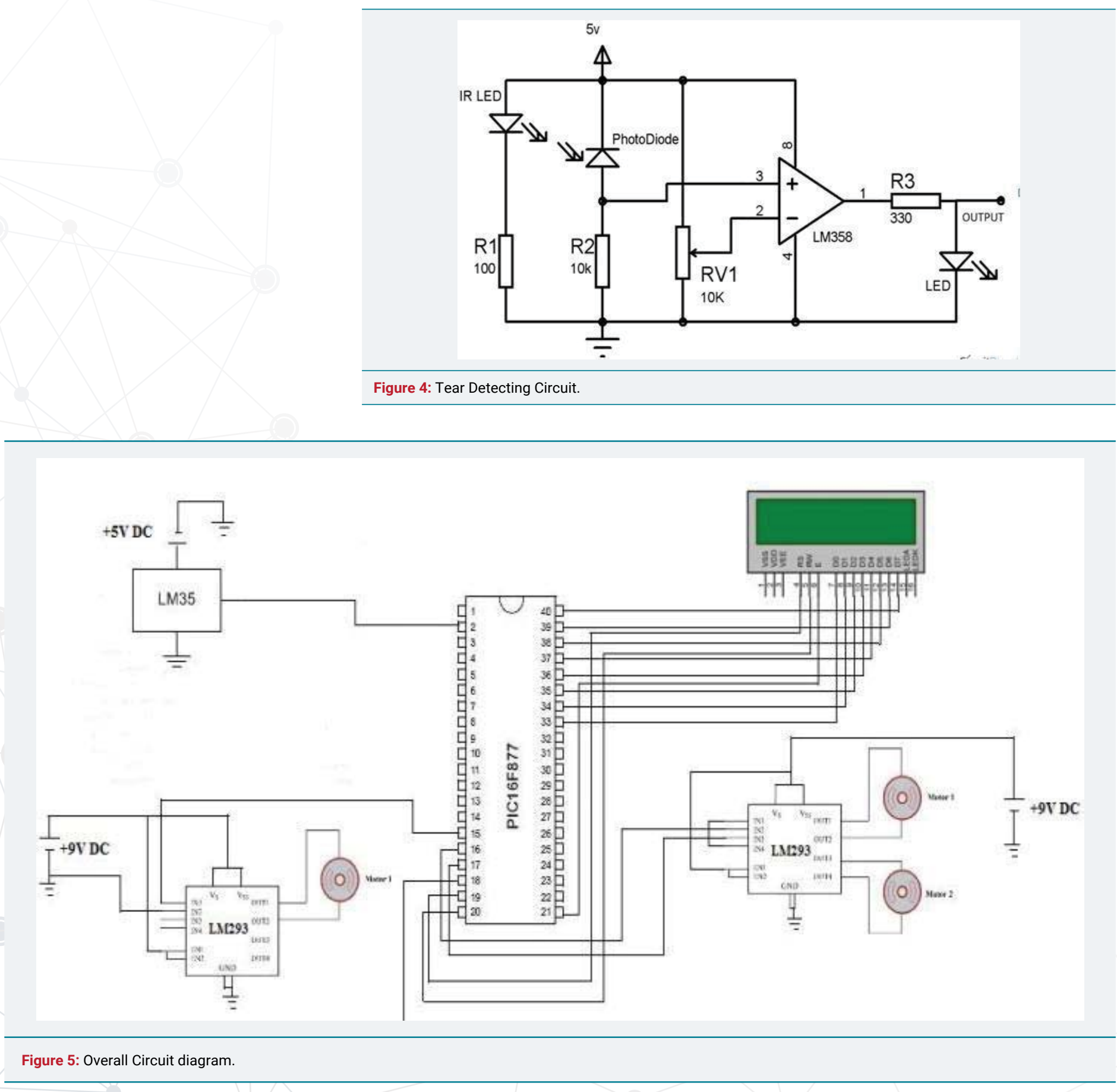


\section{Conclusion}

This Proposed system which makes use of Automatic system to regularly monitor the status of the Conveyor system is highly efficient since the operation of the Conveyor system is not at all interrupted during the occurrence of any fault in the belt. The addition of PIC microcontroller makes the overall system simple in design and operation. This system is found to be an efficient replacement for the existing manual monitoring system.

\section{References}

1. Vinoth Kumar R, Sakthivel VP, Ruban J, Imran Khan S, Vignesh M. Microcontroller based Automatic Control \& Smart Protection of Coal Conveyor System. Int J Trend Res Development. 2017. Ref.: https://goo.gl/ncL2E4

2. Chunsheng Yang, Pingyuan Xi. Dynamic simulation of the belt conveyor in neural network. Computer and Automation Engineering (ICCAE), the $2^{\text {nd }}$ International Conference. 2010; 2; 748-751. Ref.: https://goo.gl/7QT1Wx 